intestinal transit and may increase in those with naturally rapid transit. ${ }^{8}$ Meta-analysis suggests that the same effects of bran in healthy controls are also found in patients with the irritable bowel syndrome, diverticular disease, and chronic constipation. Constipated patients, however, have lower stool weights and slower transit than normal subjects whether they take bran or not. ${ }^{9}$ Interestingly, not only plant fibre in the strict definition but also the fibrous content of meat in the carnivorous diet of Eskimos and even plastic particles have similar effects. ${ }^{40}$

Scientifically well controlled studies of the effects of increasing the intake of dietary fibre in the management of constipation are few. Most have studied the effects of added bran on stool weight, stool frequency, and transit time and have shown that subjects passed bulkier, softer stools more frequently with shorter transit times when taking bran. "An increased intake of all forms of dietary fibre has a similar effect, though there are even fewer controlled studies and much evidence is anecdotal.

Some constipated people find the secondary effects of fibre-namely, flatulence, distension, and bloating - sufficiently insufferable that they cannot tolerate enough fibre to alter constipated colonic function. ${ }^{12}$ Many of these effects reduce with time, probably owing to alterations in colonic microflora, and can be minimised by increasing fibre intake gradually. A small group of young women with "idiopathic slow transit constipation"13 and others with difficulty in rectal expulsion ${ }^{14}$ are not helped by an increased intake of fibre, but they are a tiny minority of those with constipation.

\section{Development of the bran wagon}

High fibre diets can help relieve constipation naturally in almost all patients, including those with the irritable bowel syndrome. The benefits may be limited by poor tolerance and by dietary inflexibility, particularly in elderly people for whom supplements may be better than changing eating habits. Fibre intake should probably be mixed and increased gradually over weeks or even months. Wheat bran is most effective in relieving constipation, though it is less palatable and often poorly tolerated by those used to a refined diet.
The benefits of wholemeal foods in constipation have been known since ancient times. Bran was identified as the essential factor in the nineteenth century by Allinson and subsequently by Kellogg, Dimock, and others. ${ }^{11}$ In the second world war Cleave carried out crucial clinical experiments at sea ${ }^{15}$ and subsequently stimulated the new wave of interest in fibre. ${ }^{16}$ Burkitt, Trowell, Painter, and others combined epidemiological and clinical observation to postulate the "fibre hypothesis," which attempted to attribute many Western illnesses in addition to constipation to a low intake of fibre or a high intake of refined carbohydrates. ${ }^{17}$ By the early 'seventies the bran wagon was rolling enthusiastically. Time has shown that not all claims for the benefits of high fibre diets can be substantiated ${ }^{18}$ but certainly in relieving constipation, high fibre diets work.

I Kamm MA. Constipation. Br f Hosp Med 1989;41:244-50.

2 Thompson WG, Heaton KW. Functional bowel disorders in apparently

healthy people. Gastroenterology 1980;79:283-8.
3 Stephen AM, Cummings JH. Mechanism of action of dietary fibre in the human colon. Nature 1980;284:283-4.
hephen AM, Cummings JH. Mechanis

4 Ornstein MH, Baird IM. Dietary fiber and the colon. Mol Aspects Med 1987;9:41-67.

5 Cummings JH, Southgate DAT, Branch W, Houston H, Jenkins DJA, James WPT. Colonic response to dietary fibre from carrot, cabbage, apple, bran and guar gum. Lancet 1978; i:5-9.

6 Heller SN, Hackler LR, Rivers JM, et al. Dietary fiber: the effect of particle size of wheat bran on colonic function in young adult men. Am $\mathcal{F}$ Clin Nutr 1980;33:1734-44.

7 Findlay JM, Smith AN, Mitchell WD, Anderson AJB, Eastwood MA Effects of unprocessed bran on colon function in normal subjects and in diverticular disease. Lancet 1974; ; 146-9.

8 Harvey RF, Pomare EW, Heaton KW. Effects of increased dietary fibre on intestinal transit. Lancet 1973;i:1278-80.

9 Müller-Lissner SA. Effect of wheat bran on weight of stool and gastrointestinal transit time: a meta analysis. $\mathrm{Br}$ Med $\mathcal{F}$ 1988;296:615-7.

10 Tomlin J, Read NW. Laxative properties of indigestible plastic particles. BrMed J 1988;297:1175-6.

11 Cranston D, McWhinnie D, Collin J. Dietary fibre and gastrointestinal disease. Br f Surg 1988;75:508-12.

12 Edwards CA, Tomlin J, Read NW. Fibre and constipation. Br 7 Clin Pract 1988;42:26-32.

13 Preston DM, Lennard-Jones JE. Severe chronic constipation of young women: "idiopathic slow transit constipation." Gut 1986;27:41-8.

14 Turnbull GK, Lennard-Jones JE, Bartram CI. Failure of rectal expulsion as cause of constipation: why fibre and laxatives sometimes fail. Lance 1986;i:767-9.

15 Cleave TL. Natural bran in the treatment of constipation. Br Med $\mathcal{f}$ $1941 ; \mathrm{i}: 461$.

16 Heaton KW. T L Cleave and the fibre story. Foumal of the Royal Nazal Medical Service 1980;66:5-10.

17 Trowell H, Painter N, Burkitt D. Aspects of the epidemiology of diverticular disease and ischemic heart disease. American foumal of Digestive Diseases 1974; 19:864-73.

18 Taylor RH. Bran yesterday ... bran tomorrow? Br Med f 1984;289:69-70.
University Hospital, Nottingham NG7 2UH Robin Spiller, MRCP, consultant gastroenterologist

\section{2 When fibre fails Robin Spiller}

Donald Burkitt's hypothesis that many of the ills of Western people, including constipation, were caused by a fibre depleted $\operatorname{diet}^{1}$ certainly caught the imagination of a generation. So much so that many patients currently consulting their general practitioner complaining of constipation will have already tried unsuccessfully some form of high fibre diet.

This lack of success is due either to intolerance or to ineffectiveness. Intolerance reflects the fact that high fibre foods are an acquired taste, require more chewing, and entail major changes in cooking habits that patients may find difficult to accept. Furthermore, some fibre supplements - for example, raw bran - are distinctly unpalatable. An effective dose of fibre $(20 \mathrm{~g})$ requires the ingestion of six tablespoonfuls of bran or two Weetabix and four large thick slices of wholemeal bread ( $300 \mathrm{~g}$ ) or their equivalent. Defective dentures and failing appetite or imagination may make such an increase in intake unacceptable. Purified fibre supplements such as ispaghula (Fybogel) or sterculia
(Normacol) may be more acceptable for such patients in producing a softer, bulkier stool that is easier to pass. Lactulose is also effective, though rather expensive, and its oversweet taste does not appeal to everyone. Those who do successfully increase their intake of fibre, by whatever means, often experience the effects of increased bacterial colonic fermentation with accompanying flatulence, abdominal distension, and colic, which in some patients are sufficiently severe to lead to discontinuation of treatment. ${ }^{2}$

\section{Alternative approaches}

Although high fibre diets are undoubtedly effective in those with normal colonic function, unfortunately, those with slow transit who are likely to need the most help tend to show the least effect. ${ }^{3}$ A slow transit seems to favour a more complete bacterial degradation of fibre in the right colon, thus minimising the effect of fibre on faecal output. Furthermore, after a few weeks 
adaptation occurs and bacterial metabolism of fibre accelerates, causing a fall in the laxative effect. ${ }^{4}$ Thus patients who have initially responded well find constipation returning after two to three weeks, necessitating a rotation of the various fibre supplements to maintain any long term effect. Such patients with chronic constipation that is resistant to fibre are predominantly female and tend to have greatly prolonged colonic transit, either secondary to generalised colonic inertia or because of failure to relax the anal sphincter when attempting defecation. ${ }^{5}$ The cause of such obstructed defecation is obscure and may be due either to psychological or to neurological problems, or perhaps both, if prolonged straining leads to damage to the pudendal nerve. A pragmatic approach is to combine a bowel training regimen with an attempt to encourage appropriate relaxation of the anal sphincter either by counselling or by biofeedback. ${ }^{6}$ Psychosexual problems are common, and attention should be given to factors inhibiting defecation such as lack of privacy, inadequate time allowed for defecation, and more deep seated psychological problems, possibly from childhood.

Training programmes aim at establishing a regular pattern of bowel movements. Initial disimpaction is followed by attempts to defecate after the same meal each day. I usually recommend the period immediately after breakfast as colonic motility peaks at this time. Failure to pass motion on two successive days is followed by a suppository or enema. Regular appetising meals with a reasonable fibre content together with adequate physical exercise are also important as eating and exercise are the best natural stimulants of colonic activity. Children respond well to such regimens but, not unexpectedly, adults are more resistant.

\section{Stimulant laxatives and other strategies}

So far little has been said about stimulant laxatives, yet generalised colonic inertia is characterised by abnormally infrequent mass movements, which can in most cases by readily stimulated by a range of drugs, the best known of which are derivatives of senna. These are prodrugs that are cleaved by bacterial enzymes in the colon, where they directly stimulate colonic nerves to cause a mass movement that is usually followed by the passage of a normal stool. The efficacy and acceptability of such a treatment is attested to by its popularity with the general public. The main reason why stimulant laxatives are not used widely by doctors is that prolonged use may irreversibly damage colonic nerves and muscles. Nevertheless, the risks should be seen in perspective. The atonic, melanotic, "cathartic colon" was described in patients who had taken large doses daily over 20-40 years. Provided that stimulant laxatives are used infrequently, perhaps no more than once a week, at the minimal effective dose, they are unlikely to cause significant harm, especially in elderly people or others whose life expectancy is limited.

Bisacodyl is another contact stimulant that is useful for dealing with faecal impaction as it is effective as a suppository.

Saline or osmotic purges - for example, magnesium sulphate-though suitable for cleansing the bowel before surgery or colonoscopy, are ill suited for regular.

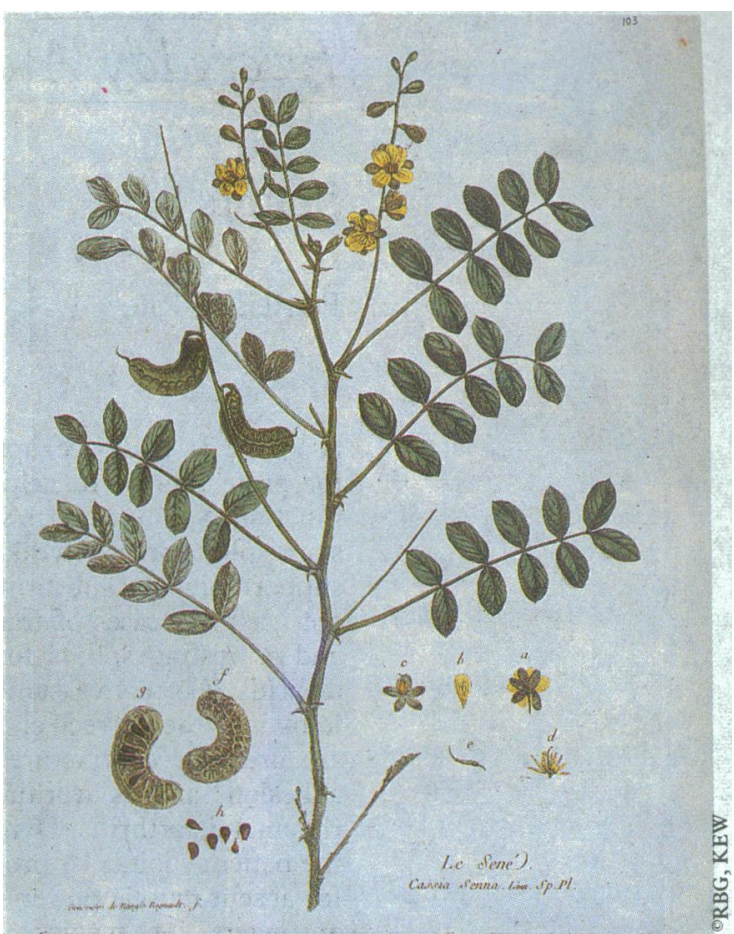

Cassia senna from Regnault's “Botanique”, volume 3, 1774

use as they result in a watery stool, considerable urgency in defecation, and occasionally incontinence. Enemas are unpleasant, both for staff and patients, but may in the last resort be necessary, as may manual disimpaction.

\section{Conclusions}

Clearly, most cases of constipation seen in general practice can be satisfactorily managed by detailed attention to diet and lifestyle, but doctors should be prepared to admit that a fair proportion of patients with severe problems will not find a high fibre diet helpful. Bowel retraining, artificial fibres, as well as occasional stimulant laxatives should then be used. In most cases this will suffice, but persistent symptoms or the need for heroic measures, particularly in younger patients, should suggest the need for more sophisticated physiological and perhaps psychological investigations in a specialist unit as some of these patients will require surgical management. ${ }^{8}$

1 Burkitt DP, Walker ARP, Painter NS. Effect of dietary fibre on stools and transit times, and its role in the causation of disease. Lancet 1972;ii:1408-11. Cann PA, Read NW, Holdsworth CO. What is the benefit of coarse wheat bran in patients with irritable bowel syndrome. Gut 1984;25:168-73.

3 Cummings JH. Constipation, dietary fibre and the control of large bowel function. Postgrad Med f 1984;60:811-9.

4 Florent C, Flourie B, Leblord A, Rautureau M, Bernier JJ, Ramband JC. Influence of chronic lactulose ingestion on the colonic metabolism of lactulose in man (an in vivo study). $\mathcal{F}$ Clin Invest 1985; 75:608-13.

5 Preston DM, Lennard-Jones JE. Anismus in chronic constipation. Dig Dis Sci 1985;30:413-8.

6 Weber J, Ducrotte PH, Touchais JY, Roussignol C, Denis PH. Biofeedback training for constipation in adults and children. Dis Colon Rectum 1987;30: 844-6.

7 Smith B. Effect of irritant purgatives on the myenteric plexus in man and the mouse. Gut 1968;9:139-43.

8 Kamm MA, Hawley PR, Lennard-Jones JE. Outcome of colectomy for severe idiopathic constipation. Gut 1988;29:969-73. 